\title{
Article \\ Explaining Differences in Scientific Expertise Use: The Politics of Pesticides
}

\author{
Dovilè Rimkutè \\ Geschwister-Scholl-Institut of Political Science (GSI), Ludwig-Maximilians-Universität München, 80538 Munich, \\ Germany; E-Mail: dovile.rimkute@gsi.uni-muenchen.de; Tel.: +49-89-2180-9055
}

Submitted: 1 June 2014 | In Revised Form: 19 September 2014 | Accepted: 7 October 2014 |

Published: 31 March 2015

\begin{abstract}
Despite the growing importance of EU regulatory agencies in European decision-making, academic literature is missing a systematic explanation of how regulatory agencies actually contend with their core tasks of providing scientific advice to EU institutions. The article contributes to the theoretical explanation of when and under what conditions different uses of scientific expertise prevail. In particular, it focuses on theoretical explanations leading to strategic substantiating use of expertise followed by an empirical analysis of single case research. Substantiating expertise use refers to those practices in which an organisation seeks to promote and justify its predetermined preferences, which are based on certain values, political or economic interests. Empirical findings are discussed in the light of the theoretical expectations derived by streamlining and combining the main arguments of classical organisational and institutional theories and recent academic research. Process-tracing techniques are applied to investigate the process by which an EU regulation restricting the use of neonicotinoid pesticides (European Commission, 2013) was developed. The empirical analysis combines a variety of data sources including official documents, press releases, scientific outputs, and semi-structured interviews with the academic and industry experts involved in the process. The study finds that the interaction between high external pressure and high internal capacity leads to the strategic substantiating use of expertise, in which scientific evidence is used to promote the inclinations of actors upon which the agency depends most.
\end{abstract}

\section{Keywords}

bee health; EU Regulation; European Commission; European Food Safety Authority; neonicotinoid pesticides; risk assessment; scientific expertise

\section{Issue}

This article is part of the special issue "The Role of Expert Knowledge in EU Executive Institutions", edited by Professor Åse Gornitzka (University of Oslo, Norway) and Dr. Cathrine Holst (University of Oslo, Norway).

(C) 2015 by the author; licensee Cogitatio (Lisbon, Portugal). This article is licensed under a Creative Commons Attribution 4.0 International License (CC BY).

\section{Introduction}

Political scientists have observed that European Union agencies have increasingly novel and far-reaching powers (Busuioc, Groenleer, \& Trondal, 2012). In addition, they argue that agencies develop over time and under certain circumstances can even gain more functions and autonomy (Coen \& Thatcher, 2005; Groenleer, 2009). Coen and Thatcher (2005) note that the role, activities and functions of these non-majoritarian regulators tend to expand, especially in less visible ways, that is, informal roles. An indicator of the rising significance of functional agencies is their central role in dealing with issues that emerge onto the EU regulatory agenda and are highly complex, ill-defined, moving in an unanticipated direction and requiring high levels of scientific expertise (Groenleer, 2009; Thatcher, 2002). However, despite academic work focusing on the growing importance of EU agencies in regulatory areas, the literature is missing a systematic explanation of how EU agencies actually function in their day-to-day activities once they have formally been created (Groenleer, 
2009). Tallberg has indicated that "the operation of the agencies, including questions of autonomy and influence have received more limited attention" (2006, p. 207) if compared to the literature on the creation and design of EU agencies (Dehousse, 2008; Kelemen, 2002; Wonka \& Rittberger, 2010).

Research looking at how agencies actually contend with their core task of providing scientific advice to EU institutions is particularly scarce. To fill this research gap the article focuses on the EU regulatory agencies acting as functional problem-solvers contributing to the regulatory decision-making process. It contributes to theoretical explanations of when and under what conditions the different uses of scientific expertise prevail. Although this question is essential to the study of epistemic politics, our knowledge on the factors explaining scientific expertise use is fragmented and lacks a systematic theoretical basis (Boswell, 2008; Schrefler, $2010,2013)$. Understanding regulatory science practices-success/failure to rely on sound scientific evidence in risk governance-is of particular importance as bodies offering independent expertise play an increasingly relevant role in EU politics and beyond (Busuioc et al., 2012; Coen \& Thatcher, 2005; Groenleer, 2009). To this end, one EU regulatory agency-the European Food Safety Authority (EFSA)-has been selected as a starting point to investigate in-depth the phenomenon of expertise use. The article contributes to the academic discussion by deepening our understanding of the causal mechanisms leading to different behaviour patterns in expertise use by focusing on one case within EFSA: the process by which an EU regulation restricting the use of neonicotinoid pesticides (European Commission, 2013) was developed.

In April 2012, the European Commission decided not to follow recommendations coming from the Member States, e.g. France, but to give a mandate to one of EU's regulatory agencies-the European Food Safety Authority (EFSA) - to conduct an independent assessment of the neonicotinoid pesticides ${ }^{1}$ risks for bees. Based on the risk assessment the Commission drafted a proposal suggesting that the use of three relatively new and very commonly used pesticides belonging to the neonicotinoid family has to be limited. As a qualified majority was not reached (15 Member States supported the proposal, 4 abstained and 8 voted against), the Commission made a final call to approve the proposal, reasoning that EFSA's scientific conclusions (2013a, 2013b, 2013c) clearly identified that ne-

\footnotetext{
${ }^{1}$ Neonicotinoids are a new class of insecticides that dominate the market place as they are considered to be effective. They cause paralysis and death of insects damaging plants. However, there are major concerns that neonicotinoid pesticides have untargeted effects as they may play a role in recent pollinator declines. For more information see: http://www. beyondpesticides.org/pollinators/chemicals.php
}

onicotinoids constitute an acute danger for bees. In 2013, the Commission adopted the proposal. The Commission made an official declaration and stressed that it had chosen to rely on the science-based arguments coming from the independent EU agency rather than the divided positions of Member States and the influence of the pesticide industry. This suggests that EFSA's scientific opinions had a central role and led to a major policy change, i.e. restricting the use of the most commonly used insecticides.

A puzzle arises when one looks at regulatory approaches to neonicotinoids outside the EU. That is, the situation regarding the neonicotinoid family of pesticides in the EU and the US as well as Canada is notably different: while Europe was banning the neonicotinoids for two years, the US and Canada were renewing the provisional registration of neonicotinoids for an additional two years. Yet, many of the same studies EFSA has used to fill information gaps on the side-effects of these pesticides on bees are applicable in the US. At this point, the question is: why different regulatory agencies provide different recommendations on the basis of the same evidence?

To approach this puzzle theoretically, this article explores the literature on expertise use. The role of scientific expertise in regulatory activities has been widely discussed within the political science field of studies (Boswell, 2008, 2009a; Hertin et al., 2007; Radaelli, 1995, 2009; Rimkute \& Haverland, 2014; Schrefler, 2010, 2013; Weiss, 1979). Political scientists are in agreement that expertise can have many functions in the policy/decision-making process. On the contrary, when it comes to explaining when and under what conditions the use of expertise varies, the existing literature leaves several gaps which this article aims to fill.

Firstly, political scientists argue that the task of providing scientific outputs, which are based on expertise rather than interests or values, becomes challenging if uncertainty is high (Boswell, 2008), the heterogeneity of external actors' interests is great (Blom, Radulova, \& Arnold, 2008), a deep ideological division is present (Skogstad, 2003) or increasing political saliency of an issue at stake can be observed (Schrefler, 2010, 2013). However, a problem occurs when one attempts to grasp which of these explanatory factors (uncertainty, interest heterogeneity, ideological division, level of conflict, political saliency, etc.) are defining, what the theoretical foundations of these explanatory variables are and how they can be combined into a theoretically coherent causal explanation. That is, we lack a detailed theoretical understanding of the mechanisms that induce different behavioural patterns in expertise use. As a result, the article aims to address this fragmentation by approaching the separate explanatory factors as a totality of causal mechanisms leading to the outcome and by systematically theorising how the causal process unfolds. In so doing, the ar- 
ticle relies on the literature of sociological institutionalism and argues that an increase in conflict, saliency, etc. is not a sufficient condition to lead to the specific use of expertise. The external environment and demands affect the use of expertise only if they translate into the actual formal and informal pressures towards the expertise organisation, e.g., agency.

Secondly, the above-mentioned stream of literature extensively focuses on the external environment affecting the behaviour of agencies (Skogstad, 2003) and to a significantly smaller extent on the internal environment and capacities of agencies (see Boswell, 2008, 2009b; Schrefler, 2010). That is, the literature aiming to explain the use of expertise has a one-sided focus as it only addresses the internal environment of expertise bodies to a limited degree. On the contrary, the recent academic work focusing on EU agencies' autonomy and functions argues that agencies are multifaceted social bodies that given the circumstances may apply diverse strategies to carry out the tasks they receive from the European Commission in order to reach their goals, survive, or increase influence (Busuioc et al., 2012; Groenleer, 2009). This suggests that both external and internal dimensions have an explanatory power in defining when the different behavioural patterns in expertise use by the agency occur.

Consequently, the article suggests a theoretical explanation derived by streamlining and combining the main arguments of classical organisational and institutional theories and recent academic research. It argues that whether the regulatory policy process can yield efficient and credible problem-solving solutions is contingent upon both (1) the external environment in which a certain scientific output production process takes place, i.e. the level of formal and informal pressure (DiMaggio \& Powell, 1983) and (2) the internal agency's capacity to produce science-based outputs (Scott, 1998). By taking this theoretical approach, the article contributes to the discussion by systematically theorising which external and internal circumstances (and how) generate diverse expertise uses. Nonetheless, even though the article introduces all possible theoretical expectations of how the interaction between two causal factors, i.e., formal and informal pressure and scientific capacity, lead to the hypothetical outcomes-problem-solving, strategic political, strategic substantiating and symbolic uses of expertisein the empirical part, the study focuses only on one causal configuration-high formal and informal pressure and high internal capacity-which is a combination of conditions expected to lead to the strategic substantiating use of expertise. In so doing, it lays a theoretical basis to study the causal mechanisms leading to expertise use practise in which scientific knowledge is used to rationalise the preferences and interests of the most influential actors in a particular policy arena.

To test this theoretical expectation, the aforemen- tioned case of the neonicotinoid pesticides risk assessment for bees has been selected. The features of the internal and external environment within which EFSA had to develop a scientific conclusion make the neonicotinoid case suitable, i.e., a crucial case (see Rohlfing, 2012), for testing how the environment of EFSA affects its behaviour regarding scientific expertise use. Specifically, the case has been selected as it possesses a high capacity to produce scientific expertise because it successfully mobilised internal human resources: the largest EFSA's unit-the Pesticides Unitwas in charge of drafting scientific outputs. In addition, EFSA had much sound external research evidence at its disposal when drafting scientific conclusions: extensive sources of expertise, data, knowledge, and understanding of honeybees and the neonicotinoid pesticides.

Regarding formal and informal external pressure, the environmental field in which EFSA had to deliver its scientific conclusions consisted of defined opposing positions (laboratory research vs. field research) and the conflicting configurations of inter-organisational structures competing with each other (industry vs. beekeeping associations and NGOs). The biggest chemical manufacturers in Europe, Bayer CropScience, Syngenta $A G$, have been actively involved in the process and in due course have filed legal actions challenging the Commission's restrictions and accused the Commission of not relying on the entire scientific evidence available and, in so doing, they challenged the EU pesticide regulation. Furthermore, independent academic experts seem to be divided regarding the issue. Besides the divergence between scientific experts, the issue of bee health has received much public attention. The topic was widely discussed in media at national, international and European levels. EU citizens could follow the decision-making process and read about the positions of key actors and the state of scientific evidence. As a result, civil society became actively involved. The activist group Avaaz initiated an online petition to immediately ban the use of neonicotinoid pesticides: 2.6 million people have signed the petition. Civil society expressed its strong feelings and a clear position on where it stands on this issue by organising protests against "mega-corporations" and funding opinion polls showing public sensitivity towards the issue.

This article is organised as follows: In section two, the theoretical approach is introduced, four hypotheses explaining when and under what conditions different behavioural patterns in expertise use occur are presented. Yet, the theoretical discussion focuses on the factors leading to the substantiating use of expertise. In section three, the research design and empirical basis are introduced. Then, section four, the article proceeds with an in-depth analysis of the process in which EFSA contributed to the EU decision-making. Finally, section five presents the key findings, concluding remarks and develops starting points for further research. 


\section{Theoretical Framework: The Use of Expertise}

\subsection{Types of Expertise Use}

Regulation in such policy areas as medicines, food safety, disease prevention or environmental protection contains high uncertainty and necessitates technical expertise, scientific knowledge, sound evidence or risk analysis (Versluis, van Keulen, \& Stephenson, 2011). The inclusion of non-majoritarian risk assessors and regulators in the EU regulatory processes offers different policy-making options; that is, policy outputs based on technical expertise and scientific knowledge coming from so called independent expertise bodies rather than from the unevenly distributed preferences of political actors (Héritier \& Rhodes, 2011). The main idea behind this line of argument is the separation of two main elements present in the policy-making process: "[...] functional, expert policy-making from broad democratic decisionmaking processes [...]" (Héritier \& Rhodes, 2011, p. 163), which, in turn, is supposed to ensure credible decisions.

In the discussion on how expertise is used by nonmajoritarian institutions, a functionalist approach brings us to the effective problem-solving dimension by treating non-majoritarian regulators as functional problem solvers possessing expertise and providing policy-makers with the sound information and evidence needed for well-informed decisions (Majone, 1996). The functionalist approach explains the delegation of certain tasks to independent bodies as the need for collective action, the necessity to resolve commitment problems as well as to overcome information asymmetries at the EU level (Thatcher \& Stone Sweet, 2002). This approach brings us to the first category, i.e. problem-solving use of expertise.

It seems that the EU's institutional architecture in risk governance is built accordingly. The duties of risk assessment and risk management are divided between two different bodies, which are also independent of each other: EU agencies and the European Commission. EU agencies have the task of assessing risk by producing independent and transparent scientific outputs and providing EU institutions, in particular the Commission, with scientific recommendations. This institutional structure is claimed to assure independent and scientificallybased risk assessments which later result in risk management activities assigned to the Commission.

EFSA, for instance, describes itself as the keystone of European risk assessment providing independent scientific advice and communication on various risks related to food and animal feed. The duties of EFSA as specified in its establishing regulation, Regulation (EC) No 178/2002 (European Parliament \& Council of the European Union, 2002), entails providing scientific and technical support for the Community's legislation and policies in all fields related to food and animal feed safety-related issues. That is, EFSA receives requests for scientific opinions: "the request outlines what is being asked of EFSA: the issue, the terms of reference, the timeframe, etc." (EFSA, n.d.). Provided that EFSA agrees to accept a request, they and the Commission settle a mandate that specifies the final terms of reference and an agreed deadline. A request results in the provision of a scientific opinion by one of EFSA's Scientific Panels. Besides this, EFSA is entitled to engage in so-called "self-tasking" activities. "Self-tasking" occurs when EFSA detects a particular issue that requires further analysis and research. This institutional architecture assures a separation of scientific and political tasks, which, according to the functional approach, creates an environment in which a problem-solving logic is likely to prevail.

However, the view that agencies provide impartial information seems to be in conflict if one looks at the regulatory bodies not simply as functional problem solvers, but also as self-interested players who may pursue their policy goals and strive to protect their independence and the legitimacy of their institution, which is commonly embedded in an unsettled organisational environment (Coen \& Thatcher, 2005; Groenleer, 2009; Majone, 1996). Although agencies clearly use information to solve regulatory policy problems, they may also use expertise strategically to advance their individual or organisational interests, or those of the most influential actors.

In the literature discussing the problems of technocratic legitimacy, so called independent expertise bodies are argued to follow policy preferences imposed by political actors (Shapiro, 1997), which, in turn, results in decisions promoting the distribution of values, rather than credible, apolitical and value-free decisions. Here, expertise is a source of power and legitimacy to nonmajoritarian regulators and they may use it in the ways which are advantageous to the agency and its survival, rather than to produce efficient problem-solving outputs (Boswell, 2008, 2009a; Schrefler, 2013). This means that the day-to-day functioning and the actual behaviour of agencies do not necessarily coincide with their image, i.e. providers of "neutral" information which is communicated to the wider public (Groenleer, 2009). This approach brings us to strategic political, strategic substantiating and symbolic expertise use strategies.

The strategic use of expertise is divided in two subcategories in the literature on this topic: (1) politicalthe motivation behind this type of expertise use is related to the goal of increasing political powers, influence, resources or/and to strengthen prestige, status or reputation, and (2) substantiating-the agent seeks to support or justify pre-set inclinations (Herbst, 2003; Schrefler, 2010). Furthermore, expertise can also be used to imitate what the most important actors/institutions do and require in general. In so doing, agencies can demonstrate their competences in what they are doing without actually engaging in substantial 
activities - symbolic use of expertise. In this case, the use of expertise is "triggered by the explicit intention to emulate what has been done by the "leaders'" (Radaelli, 2009 , p. 1150) and similar institutions in the field.

\subsection{Explaining Differences in the Use of Expertise}

The remainder of this section proceeds in two steps: the general theoretical argument and hypotheses are introduced, followed by a specification of the causal mechanisms leading to the substantiating use of expertise.

DiMaggio and Powell (1983) aim to explain homogeneity of organisational forms, practices, and structures, i.e. incremental change using institutional isomorphism theory. This theory also focuses on the political struggle of organisations to gain power and survive. They argue that one of the reasons for incremental change is formal and informal pressure coming from other organisational bodies upon which an organisation depends. "Coercive isomorphism stems from political influence and the problem of legitimacy" (DiMaggio \& Powell, 1983, p. 150). Instead of focusing on one particular actor, the principal, as is emphasised by the P-A model, the sociological institutionalist approach focuses on the analysis of the organisational field. In so doing, the attention is paid to a variety of actors and their relative influence.

This article argues that the level of pressure coming from external actors, both political and non-political, makes a difference because the legitimate right of EU agencies to contribute to EU decision-making plays the key role in the debates on EU agencies' legal powers (Chiti, 2013; Hofmann \& Morini, 2012) and de facto independence (Maggetti, 2012). That is, EU agencies are supposed to be an engine of expertise-based decisions within the EU and to derive their legitimacy by delivering unbiased and well-informed outputs (Borràs, Koutalakis, \& Wendler, 2007). However, to survive and adapt, organisations reflect the formal and informal rules that are institutionalised and considered to be legitimate in a certain environment. For this reason, organisations are structured "around rituals of conformity to wider institutions" rather than concerned with their technical activities and production of outputs, which are technically valid (DiMaggio \& Powell, 1983, p. 150). That is, organisational survival and success are defined by other factors than productive activities (Meyer \& Rowan, 1991). Despite the fact that organisations are supposed to rely on expertise and evidence that are available, they have to produce outputs and develop behavioural patterns which lead to the increased legitimacy and resources needed to survive and gain credibility. To some extent this depends on an organisation's capacity and strategies to imitate and adapt to the environment in which they are based (DiMaggio \& Powell, 1983).

Even though these theoretical approaches stress the importance of external influences on organisations' behavioural strategies, this should not go too far and assume that the causal relationship is one-sided (Scott, 1998). Organisational literature argues that organisations not only have to be seen as a part of the context surrounding them, but also as individual actors in their own right with the power to take action and use resources. The behaviour of an organisation is not only defined by its level of formal and informal pressure and attempts to satisfy key actors by taking a "common interest" on board. The capacity of organisation to produce expertise and manage internal issues is equally relevant (Borràs et al., 2007; Brunsson, 1989; DiMaggio \& Powell, 1983; Schrefler, 2010; Skogstad, 2003). At this point, the operational level of the organisation becomes important in defining how epistemic authority is exploited.

The two dimensions are closely related: taken together they are expected to influence the behaviour of organisations. The explanations referring to the diverse strategies for using expertise cannot be seen as a straightforward relationship between simple independent factors, rather they need to be studied in terms of combinations of various conditions which are necessary for the occurrence of a certain outcome. In this article, two interacting conditions-external pressure (high/low) and internal capacity (high/low)-are argued to make a difference to the outcome in the absence of all other conditions related to the outcome (Rohlfing, 2012) (see Table 1).

Table 1. Theoretical expectations.

\begin{tabular}{|c|c|c|c|}
\hline${ }^{2}$ & iension & Formal & hal pressure \\
\hline & & Low & High \\
\hline Internal capacity to & High & Problem-solving & Strategic substantiating* \\
\hline outputs & Low & Strategic political & Symbolic \\
\hline
\end{tabular}

Note: *Empirically tested in this article. Strategic substantiating expertise use hypothesis: expertise is used for strategic substantiating purposes (as opposed to problem-solving, political or symbolic purposes) when the level of pressure coming from the external environment is high (as opposed to low) and an organisation has a high scientific capacity (as opposed to low). 
In the remainder of this article, a brief introduction to all theoretical expectations is followed by the specification of observable implications. However, the main theoretical and empirical focus remains on the substantiating use of expertise.

Problem-solving: Provided that the organisation has a high capacity to produce scientific outputs (i.e. human resources, sound scientific evidence), the absence of interference with an agency's activities enables the agency to direct its activities to the problem-solving use of its available scientific expertise. If the problemsolving use of expertise is employed, one should empirically observe strict adherence to scientific standards: a comprehensive description of the data included in the scientific outputs; a clear description of the inclusion/exclusion criteria of evidence; acknowledgement, identification and description of any uncertainties; and independent and balanced scientific conclusions.

Strategic political: An inability to produce outputs based on sound evidence is likely to be concealed in order not to lose status, reputation and power. Organisations that use epistemic authority rather than admit that a task exceeds their capabilities can maximise their legitimacy and increase their resources and survival chances (Scott, 1998). In this case, one should empirically observe the attempts of organisation to enhance prestige/reputation and expand powers/ influence (Boswell, 2008; Weiss, 1979). The organisation attempts to establish or maintain its stance in the field. Consequently, expertise is used to gain legitimacy in respect to other actors/institutions, rather than to find a solution to a specific problem (Boswell, 2008).

Symbolic: Here, the organisation has to respond to external pressures. However, as the scientific capacity is missing, the organisation follows similar structures and responds to expectations or external pressures by simply accepting what has been done by relevant actors in the field (Schrefler, 2010; Radaelli, 2009). In this case, one should empirically observe the replication and repetition of what has already been concluded by other bodies, e.g., other EU agencies/institutions, international organisations or influential bodies outside the EU, e.g. US authorities.

Strategic substantiating: The combination of high capacity and high external demands results in the substantiating use of evidence as the organisation is able to actively respond to the pressures and demands by suggesting convincing outputs in line with the preferences of the most influential actors (DiMaggio \& Powell, 1983; Skogstad, 2003). That is, "[t]he greater the dependence of an organisation on another organisation, the more similar it will become to that organisation in structure, climate, and behavioural focus" (DiMaggio \& Powell, 1983, p. 154). The organisation has to be prepared to respond to demand by using evidence in the way required of it. Diverse environmental circumstances call for different organisational actions and frame a specific context providing organisations with both constraints and opportunities (Scott, 1998). If the organisation's internal capacity to deal with external pressure matches with the external demands, organisations are likely to adapt and grow in terms of power and influence. For instance, organisations that receive negative/positive responses or requests to revise outputs may seek to revise their goals and outputs so that they meet the external expectations of key actors, both political (i.e., the Commission) and nonpolitical (e.g. organised interest groups).

As the article focuses on uncovering the causal mechanisms leading to substantiation use of expertise, the following paragraphs introduce the expected causal process. The task of providing scientific outputs based on sound expertise becomes challenging if "an increase in the extent of interaction among organisations in the field; the emergence of sharply defined inter-organisational structures of domination and patterns of coalition; an increase in the information load which organisation in a field must contend; and the development of a mutual awareness among participants in a set of organisations that they are involved in a common enterprise" (DiMaggio \& Powell, 1983, p. 148) can be empirically observed. To explain, organisations are engaged in interdependent activities, they are dependent on the exchange of information, and have a role in linking (competing) coalitions (Scott, 1998). The task of delivering scientific advice on a specific issue opens room for debate and interaction with external actors; that is, organisations have to collect and review existing evidence, and consult various experts and information sources. As EU agencies are dependent on information provided by external actors, they are open to various sources of evidence in order to be able to make well-informed recommendations. In so doing, a wider variety of actors becomes directly and indirectly involved in the process. This, in turn, might increase the intensity of interaction and interdependence (Brunsson, 1989; Schrefler, 2010, 2013). The intensity of interaction increases with the amount of information coming from various sources that point to different decision options (DiMaggio \& Powell, 1983). An increase in the extent of interaction between organisations in the field and interdependence results in the formation of sharply defined inter-organisational structures and coalitions as the participants in a set of organisations become mutually aware of each other's existence and positions regarding an issue at stake (DiMaggio \& Powell, 1983). That is, external groups with a common interest form coalitions that have sharply defined positions. The attention of the media intensifies as a result of competing positions and contradictions coming from different sources of information, which, in turn, results in the intensification of saliency of the issue (see Schrefler, 2010). Civil society becomes actively involved because it is able to observe how the process evolves 
and what the rival positions of key actors are.

The key players in the environmental field will try to influence those actors who are responsible for drafting scientific outputs and have a great influence on the final outcomes, e.g. agencies (Skogstad, 2003). External actors may use various (formal and informal) instruments to influence the functional organisations. These include: constraints by political actors, e.g. stringent mandates for a specific task, tight monitoring and supervision, or attempts to capture the agency by external organised groups, e.g. by providing expertise (DiMaggio \& Powell, 1983). The pressure comes in the form of force, persuasion, or an invitation to join the mainstream position of relevant actors in the environmental field, i.e. the totality of relevant actors (DiMaggio \& Powell, 1983).

In order to test the strategic substantiating expertise use hypothesis, one should focus on the inclusion/exclusion criteria of scientific evidence that is considered by the agency: are the exclusion/inclusion criteria clear and transparent; do they follow the established practices of evaluating evidence (instead of introducing new practices)? In the case of substantiating use of expertise, one should empirically observe clear patterns of the one-sided use of scientific evidence that supports the interests of key actors in the environmental field, i.e. the actor on which organisation's survival and legitimacy depend most. If the agency deliberately collects evidence that supports a specific position and aims to confront opponents, rather than relying on a full range of scientific evidence, this implies a substantiating application of expertise (Boswell, 2008; Hertin et al., 2007). Evidence that coincides with preferred positions, which are made based on political or economic interests, is employed to take decisions and to gain superiority over alternative positions (Hertin et al., 2007). According to Boswell (2009b), the substantiating use of knowledge enables the agent to gain support and approval for the choices they make when taking important decisions.

\section{Research Design}

This article proceeds with the within-case level analysis to understand the theory-based explanations that specify the linkage between causal factors and outcomes (Blatter \& Haverland, 2012; Rohlfing, 2012). The empirical analysis is centred on a single case, as such an approach facilitates the theoretical goals of the article, i.e. to provide sufficient proof of a causal relationship and to trace whether the causal process unfolded as expected. An in-depth analysis of one particular case allows explaining the phenomenon as fully as possible, which is needed when tracing how causal mechanisms unfold. In so doing, the article fills a research gap left by political scholars investigating the phenomenon of expertise use. However, the single case research strategy selected for this research entails some weaknesses, i.e. it does not allow generalisation covering a wider range of cases (Rohlfing, 2012). Therefore, further research is needed to test if the same patterns unfold in other $\mathrm{EU} /$ national agencies or international/national/regional independent expertise bodies providing scientific advice.

Cases that meet the theoretical requirements, i.e. high capacity and high pressure, are suitable for testing the hypothesis (Rohlfing, 2012). The case selection strategy applied in this article-typical cases ${ }^{2}$-allows for generalisation regarding other cases which are close to the selected case in terms of distribution, i.e. meet the same causal conditions. That is to say, the empirical conclusions regarding neonicotinoid pesticides can arguably be used as a basis for generalisation for cases within EFSA that have been developed under the same internal and external conditions: high capacity and high external pressure. Such cases could be GMOs, nutrition, bisphenol A, flavourings, food additives, etc. However, one must note that the conditions under which the agency has to provide expertise can vary over time. For instance, EFSA has conducted risk assessments on bisphenol A several times, each time under different conditional combinations. Therefore, only the risk assessment on bisphenol $A$ in relation to baby feeding bottles has undergone similar processes to the neonicotinoids case. In short, generalisation is not issue-specific. On the contrary, generalisation is plausible in terms of the combinations of various conditions that are necessary for the occurrence of a certain outcome.

To increase the validity of empirical data this study relies on data triangulation. Several sources of independent evidence are employed: publicly available information, e.g. scientific outputs, press releases and ten semi-structured interviews; direct observations, e.g. public speeches at the events attended. ${ }^{3}$ The interviewees were selected based on their activities regarding the health of bees and scientific expertise (only scientific experts were interviewed to keep the discussion at the scientific level). The selected interviewees are the key scientific experts, both academic (5 interviewees) and industry (5 interviewees) and have directly or indirectly contributed to the development of the neonicotinoid regulation. The interviews were conducted between the $18^{\text {th }}$ of November 2013 and the $4^{\text {th }}$ of February 2014. The length of the interviews varies from 39 to 82 minutes.

\footnotetext{
2 Typical cases refer to cases which are representative within the group they are assigned to and different from the group they do not belong to (see Rohlfing, 2012).

3 Attended events: (1) EFSA Scientific Colloquium XIXBiodiversity as Protection Goal in Environmental Risk Assessment for EU, 7th-28th November 2013, organised by EFSA, Parma. (2) Conference for Better Bee Health, 7th April 2014, organised by the European Commission, Brussels.
} 


\section{Empirical Analysis}

\subsection{Two Interacting Explanatory Factors: High Internal Capacity and High Formal and Informal Pressure}

The Commission's decision to give a mandate to EFSA to conduct an independent scientific evaluation on the neonicotinoid pesticides has its roots in recent scientific developments and the work of academic scientists who prompted the Commission to address the risks of neonicotinoids to bees. ${ }^{4}$ The Commission requested a review of this new scientific knowledge regarding the role of active neonicotinoid substances, reasoning that the neonicotinoid pesticides have already been under scrutiny in the academic community - scrutiny which resulted in new findings on the issue. ${ }^{5}$ In recent years, scientists' attention focused on neonicotinoids which, in turn, encouraged academic and non-academic experts from advancing scientific understanding of the effects of neonicotinoids on bees: "The whole discussion picked up speed after the Colony Collapse Disorder phenomenon in the US in 2006, there were a lot of scientific projects in the area, basically a lot of laboratory studies." ${ }^{6}$ Industry, on the contrary, was interested in maintaining its product's place on the market, and therefore invested a lot of money in field research to provide evidence that the product is safe. Consequently, there is more expertise, data, knowledge, and understanding of honeybees and the neonicotinoid pesticides relative to other stressors affecting bee health. Pesticides and honeybees have featured heavily in discussions on the health of bees. ${ }^{7}$ Experts argue that existing knowledge in the field is relatively rich and the capacity of EFSA to address this issue was high as they managed to mobilise internal resources, i.e. the Pesticides Unit.

However, besides the high capacity of EFSA to produce scientific outputs on the topic, constant external demands can also be empirically observed. To illustrate, concerns about neonicotinoids were initially raised in France after the launch of imidacloprid and its use as a seed treatment of sunflowers. ${ }^{8}$ Concerns among French beekeepers persisted and the French regulatory authorities eventually responded in a precautionary manner by banning the product. Data was re-evaluated from time to time, and the ban on neonicotinoids was lifted and re-established. The academic expert suggested that "to some extent it looks as if French authorities have possibly responded to whatever pressures from the different stakeholders being passed

\footnotetext{
${ }^{4}$ Academic expert \#2, Industry expert \#3, \#7

5 New scientific evidence available: e.g., Henry et al. (2012), and Whitehorn, O'Connor, Wackers and Goulson (2012).

6 Industry expert \#10

7 Academic expert \#4

8 Industry expert \#3; Academic expert \#6
}

from whether-the ministry, the government, industry, beekeeping or farming communities-differently at different points in time. But the way they switched from allowing to not allowing suggests that there were some pressures applied." ${ }^{\prime 9}$ Eventually, this political debate was transferred to the EU level.

EU institutions, i.e. the European Parliament and the European Commission, called for actions regarding the neonicotinoid pesticides risk assessment for bees at the EU level as the European bee population plays a vital role in both pollination and the production of honey and other products within the EU: pollinators contribute 22 billion Euros each year to European agriculture as 84 per cent of crops need insect pollination, more than 80 per cent of wild flowers require pollinators to reproduce (European Commission, 2014). For this reason, the decline of the bees raises strong concerns in the European Community. The issue has received a particular attention from the European institutions. For instance, the European Parliament played a significant role in bringing the issue to the EU agenda. ${ }^{10}$ The European Commission has laid down specific EU rules to protect and maintain the health of bees within the EU.

The EFSA's scientifically-driven process of understanding the risks caused by the pesticides was particularly monitored and strongly criticised or supported by a wide variety of institutional and non-institutional external actors. ${ }^{11}$ The case can be characterised as having many external actors actively involved in the process of scientific output drafting, including both political and non-political actors, e.g. industry, academics, national regulatory authorities, and civil society. Scientific experts invariably refer to high external pressure when they discuss the performance of EFSA and the Commission's commitment to taking decisive action in this particular case. According to the interviewees "strong political NGO pressure (media pressure came later) created a very difficult environment for the European Commission." 12 Interviewees confirm that the bee issue involves a lot of "political dynamics and there was a lot of pressure on the European Parliament by the NGOs and individual representatives in the Parliament." One interviewee stated, "I have been personally present when the European Commission presented the EFSA results and they clearly admitted in this presentation that there was a lot of political pressure." ${ }^{13}$ The case can be characterised as politically contested as in recent decades the issue of bees' health has gained significant attention within the EU and beyond Europe.

\footnotetext{
${ }^{9}$ Academic expert \#6

${ }^{10}$ Industry expert \#3, Academic expert \#1 and \#6

${ }^{11}$ All scientific experts

12 Industry expert \#3

13 Industry expert \#8
} 
This, in turn, increased the flow of information as actors possessing information supporting their position were highly interested in providing EFSA with the evidence they possessed. The key actors in the environmental field had strongly contradicting positions and scientific evidence supporting these positions. For instance, pesticide manufacturers flooded EFSA with field research evidence, while independent academics provided EFSA with laboratory research results. NGOs and beekeeping associations provided monitoring data, arguing that the leading cause of bee population decline was neonicotinoids. As a consequence, the volume of information coming from outside was exceedingly high and contained diverse and opposing conclusions. On one side there were academics causing alarm by referring to the laboratory studies, while on the other side industry actors invariably referred to field research where neonicotinoids were shown to have no effect to honeybee mortality: "It was high profile-a lot of interest from the media, a lot of research funding for studies looking into the danger posed to bees by neonicotinoids, lots of articles published in the last two years. Many such articles suggested a problem, identified a potential hazard, or provided neonicotinoids as a possible explanation for why we see a decline in the health of bees. Yet studies carried out under field conditions told a different story." 14

The scientific debate was polarised along political lines, i.e. participants' economic and ideological wellbeing was at stake. Opposing coalitions were built to promote their own interests and to respond in a united fashion. One such coalition was made up of industry actors, while the other was the Commission strongly pressured by NGOs and beekeeper associations. ${ }^{15}$ The biggest industry companies united by attracting academics who claimed that the regulatory decision and process was highly flawed and patterns of issue politicisation can be observed. "We [industry] have got an association that can represent us-the European Crop Protection Association. On the European Commission side it was easier for them because they are getting a consistent message." 16

Besides differences of opinion among scientific experts, the issue of bee health has received a large amount of public attention. The topic was widely discussed in the media at national, international and European levels. "Bees are an emotional topic. With all the publicity that you have when you're talking bees, especially on the governmental organisation level, the pressure is high. It's clear that science is not the only basis, but to which parts other factors play into that. Most scientists, a great majority of them, are very un-

\footnotetext{
14 Industry expert \#7

15 Industry experts

${ }^{16}$ Industry expert \#7
}

comfortable how the public debate has developed."17

The article proceeds with an empirical analysis of how the specified causal configuration-high formal and informal pressure and high internal capacity to produce scientific outputs-led to the outcome.

\subsection{Strategic Substantiating Use of Expertise?}

This section focuses on the "scientific" elements, i.e. it aims to trace how scientific outputs were developed by the main scientific expertise body, i.e. the European Food Safety Authority, whose influence was defining and has led to the major policy change, i.e. the restriction of relatively new and most commonly used insecticides.

\subsubsection{A Tale of two Regulatory Approaches: Laboratory Research vs. Field Research}

As already discussed, there are contradictions to be found when comparing scientific evidence coming from laboratory studies and field research. Academic research conducted in laboratory conditions indicates the high risks associated with neonicotinoids, while industry-funded research, i.e. field research, concludes that under real conditions, neonicotinoids do not put bees at an unacceptable risk. Field research is recognised as typically more complex, incorporating many different facets and tends to be given certain prominence in regulatory decision-making due to the inherently more realistic exposure scenarios incorporated into it. ${ }^{18}$ There is recognition that laboratory research is done in a simple environment, e.g. "for honeybees that involve individuals isolated in a glass cage, where they are not exhibiting normal behaviours or have no opportunity to avoid exposure to pesticides."19 For this reason, laboratory studies are presented as the worst-case scenario but regarded as relevant for their repeatability and higher statistical power.

Academic scientists agree that the existing scientific knowledge is not in a position to relate the interpretation from laboratory to field research, and more data is needed. ${ }^{20}$ Academic experts state that, in terms of published work, they know that certain doses can lead to certain types of effects. However, scientific knowledge is limited: scientists do not know if these effects necessarily happen in field situations. They also do not know precisely what residues bees are exposed to in landscapes with diverse crops. Therefore, pesticides are recognised as a highly serious risk, however, there are many unanswered questions. Academic experts admit that "as a scientific community, we are unfortunately not in the position to give people the answers they are

\footnotetext{
17 Industry expert \#10

18 Academic expert \#2, \#6

${ }^{19}$ Academic expert \#6

${ }^{20}$ Academic expert \#6
} 
looking for now."21 Consequently, EFSA had a difficult task: to assess the contradicting evidence and to decide which evidence was valid and why. If expertise is used by EFSA for problem-solving purposes in this particular case, one should empirically observe conclusions independent from external interests, clear inclusion/ exclusion criteria for evidence used in scientific outputs, and adherence to other scientific standards (as specified in Section 2.2). On the contrary, if scientific expertise is used for substantiating purposes, one should empirically observe the clear patterns of the one-sided use of scientific evidence that supports the interests of the key actors in the environmental field (see Section 2.2.).

As noted above, the Commission has been under a lot of pressure from various organised groups to take a decision regarding neonicotinoid pesticides. ${ }^{22}$ Consequently, it issued a request (European Commission, 2012) to EFSA for a risk assessment of neonicotinoids related to their effect on the health of bees in light of new scientific knowledge and monitoring data. The point to note in the request is that the Commission asked EFSA to take into account the forthcoming "guidance document": EFSA scientific opinion on the science behind the development of a guidance document on the risk assessment of plant protection products on bees. The "guidance document" introduced a higher level of scrutiny for interpretation of field studies (EFSA, 2013d). This new EFSA scientific opinion revised and improved the level of protection regarding bees when evaluating risks posed by pesticides.

The guidance document was introduced in the middle of the neonicotinoid pesticide risk assessment and can be considered to have been a "game changer". The guidance document is seen as controversial by industry, national regulatory agencies and other implementing bodies; that is, it has received over a thousand comments from all stakeholders, including industry, and was not completely finalised by the time neonicotinoids were being evaluated (the document was finalised in July 2013 while the neonicotinoid pesticide review was published in January 2013). The majority of the data submitted by applicants, i.e. pesticide manufacturers, did not meet the new requirements and was considered inconclusive and not taken into account when drafting scientific conclusions regarding pesticides. "An EFSA review of the science behind the risk assessment for pesticides in bees - an opinion-a very large European document-changed the whole testing and risk assessment paradigm for bees, and then they assessed our [industry] existing data against that. Our data has been generated under the existing guidelines. When they evaluated this data they discounted a large proportion of data we had already conducted, and then the use of this data was not taken into account in

\footnotetext{
${ }^{21}$ Academic expert \#6

22 Industry and academic experts
}

their conclusions." 23 Consequently, when industryproduced data was held up to the new scientific standards set out in the guidance document, there were data gaps identified for many registered uses because none of field research that proved safe use were found to meet the new scientific standards. Industry claims: "The large number of data gaps identified in the EFSA review incorrectly gives an impression that industry has been negligent and ignored risks" (Campbell, 2013, p. 53). This suggests that extra efforts were taken by the Commission (and followed by EFSA) to justify the inclusion of studies proving a risk and exclude studies suggesting that there was no risk. This is an empirical observation suggesting that the evidence was used for substantiating purposes because without the introduction of new assessment standards - the new guidance document-the EFSA's scientific conclusions might have been different.

To illustrate, as discussed in the introduction of the article, the policy outcomes of EU and US regulatory authorities were different, i.e. neonicotinoids were restricted in the EU to prevent a decline in the bee population while the Environmental Protection Agency (EPA, the US regulatory authority) has a different approach and risk communication strategies. EPA claims to focus on the safe use of neonicotinoids, rather than restricting or banning the product, even though initial concerns about the phenomenon of Colony Collapse Disorder were raised in the US (US Environmental Protection Agency, 2013). The differences between the two approaches are rooted in the debate over which evidence can be counted as valid, i.e. laboratory research or field research. EPA decided not to exclude any source of evidence and this led to a conclusion allowing the use of pesticides and managing and controlling the risks posed by neonicotinoids. EPA explicitly notes that they base "pesticide regulatory decisions on the entire body of scientific literature, including studies submitted by the registrant, journal articles and other sources of peer-reviewed data." ${ }^{24}$ On the contrary, EFSA was implicitly asked to follow a "conservative" approach by applying a stringent validation criterion towards evidence coming from pesticide manufacturers, which led to the exclusion of the majority of industryfunded research, i.e. field research:25 “EFSA was given a narrow mandate and the time available to complete the reviews was extremely limited. Consequently, EFSA was pushed into taking an extremely critical and highly conservative approach in their review, identifying a long list of potential data gaps and risks to bees." ${ }^{26}$ As a result, EFSA's conclusions exclusively relied on labora-

\footnotetext{
23 Industry expert \#7, the same point was mentioned by all industry experts

${ }^{24}$ See US Environmental Protection Agency (2013)

25 See Campbell (2013)

26 Industry expert \#7
} 
tory research coming from academic scientists.

Industry experts believe that the most serious weakness of the scientific conclusions of EFSA is that a considerable part of the existing evidence from field research has been rejected and considered unusable in risk assessment. ${ }^{27}$ They believe that this approach "demonstrates a bias in the standard of proof required. Evidence of potential harm seems to be easily accepted, whilst evidence of safety is subject to deep scrutiny. So even though there is a large body of semi-field and field work that shows no impact on long term health and survival of honeybee colonies, this is poorly accounted for in the risk assessment or entirely excluded, even where EFSA acknowledge the work to be of a high quality." 28 They claim that science is used politically when the reference to theoretical risks is made. ${ }^{29}$ The essence of the concept of the substantiating expertise use is precisely communicated in the interviews; industry expert stated, "that was not my impression that they fundamentally prefer academic data over industry data, but I have noticed a certain focus to rather consider data that is substantiating a concern rather than data not supporting the concern." ${ }^{30}$ Industry claims that the exclusion of field research data was a case-by-case decision, and EFSA (by taking into account the mandate of the Commission) were looking for a bigger or smaller perceived shortcoming in each study that led to their factual invalidation.

The interviews of scientific industry experts suggest that biased inclusion/exclusion criteria were used to evaluate evidence used in the scientific conclusions of EFSA. This might cast some doubts, as the pesticides industry has an enormous economic interest in keeping their products in the market. However, if one follows the entire process and triangulate data sources (i.e. relying on official documents) to find additional empirical evidence, one observes that the Commission and EFSA made extra efforts to introduce the new guidance document during the process of neonicotinoid risk evaluation. One could conclude that EFSA's scientific conclusions were in line with the problem-solving logic, if the new guidance document had been finalised before the neonicotinoid risk evaluation had started and if industry had had time to provide new data in line with the new guidelines. However, the process unfolded in reverse as external political and non-political pressures to take conclusive action against pesticides remained.

Given the scientific uncertainty, i.e. controversy, between field and laboratory research, "the political pressure was to apply the precautionary principle, which usually leans towards restriction or a ban. EFSA's report says simply "we need more evidence to be con-

\footnotetext{
27 Industry expert \#3, \#5, \#7, \#8, \#10 and Campbell (2013).

28 See Campbell (2013)

${ }^{29}$ See note 27

30 Industry expert \#5
}

clusive." 31 There has been a considerable amount of scientific data drawing into doubt the safety of these chemicals in relation to the health of bees and the academic expert confirmed: "If there is a benefit of doubt, it is on the side of bees. If industry in the coming years can provide evidence that this is not justified, these chemicals can be put on the market again." 32 Scientific experts agree that the precautionary principle was applied in response to high public interest and intense campaigning by many organisations - "it was important to be doing something." ${ }^{33}$ Furthermore, Tonio Borg, a Commissioner of the DG for Health and Consumers has publicly stated: "it was my personal concern to take a decisive action." 34

To conclude, the principle of precaution as the Commission defines it gives more freedom to justify stricter regulation in the absence of scientific certainty of actual risks. According to Majone (2002) the logic of the precautionary principle is likely to produce undesirable consequences as it can be easily misused to "justify protectionist measures" and it may promote distributive consequences that are against the logic of the problem-solving use of expertise. Such a model can lead to extrapolation from a toxicological experiment with the most sensitive species and maximum doses to conclusions referring to high risks in the realistic conditions (Majone, 2002). For instance, in the neonicotinoids case, the problem of extrapolation from laboratory research to risk in field conditions can be observed. This observation hints at broader generalisation, as the precautionary principle in the EU is used beyond food safety issues (e.g. genetically modified organisms). The principle of precaution is also used to ensure a higher level of environmental protection at the EU (see Tosun, 2013).

\section{Conclusions}

Recent academic literature has increasingly focused on EU agencies' formal and informal powers, and novel and far-reaching functions and influence. The article discusses these issues by examining the scientific dayto-day activities of one EU agency-the European Food Safety Authority (EFSA) - to trace how scientific expertise is used when the agency has to provide a scientific conclusion under a particular set of environmental conditions, i.e. high formal and informal pressure and high internal capacity to produce scientific outputs.

In the case of neonicotinoid pesticides, the European Commission made it explicit that the EFSA's scientific conclusions and not the Member States' positions

\footnotetext{
31 Industry expert \#3

32 Academic expert \#1

${ }^{33}$ Academic expert \#6

${ }^{34}$ Official speech at the Conference for Better Bee Health, 7th April 2014, organised by the European Commission, Brussels.
} 
were crucial in the regulation restricting the use of pesticides. This leads us to believe that the need for expertise is one of the factors influencing the shifting authority from classical EU institutions and the unevenly distributed preferences of Member States to new nonstate actors, i.e. agencies. However, an in-depth analysis of a single case study conveys a slightly different message: particular environmental circumstances call for different organisational actions and frame a specific context providing expertise organisations with constraints to use expertise in a required way and opportunities to grow in terms of power and influence, provided that the organisation acts as expected.

The article concludes that the interaction between high external pressure and high internal capacity to respond to this pressure leads to substantiating use of expertise, in which scientific evidence is used to promote the inclinations of those actors on which the agency depends most. One cannot observe the problem-solving logic because the process in which EFSA delivered scientific outputs did not follow common standards: extra measures were taken to rely on one particular source of expertise and scientific conclusions were unbalanced and vague. Symbolic practices were also absent as EFSA did not imitate what national agencies or the US authorities had concluded, on the contrary, it conducted a new risk assessment, introducing a different approach. Finally, EFSA did not engage in strategic political activities.

Multiple sources of evidence suggest that a strategic substantiating expertise use logic was followed. Empirical evidence of a single case study suggests that the line between risk assessor (EFSA) and risk manager (the Commission) is blurred, as the Commission in this particular case played an important role in predefining the conditions under which specific tasks should be carried out. As was illustrated with the comparison between the US and the EU, the differences between two approaches, i.e. EFSA and EPA (US authorities), are rooted in the debate as to which evidence counts as valid and reliable for drawing regulatory conclusions. The article argues that the narrow and stringent mandate provided a basis for one-sided scientific conclusions right from the outset. EFSA was implicitly asked to apply a rigid validation criterion towards evidence coming from pesticide manufacturers, i.e. field research, which led to the exclusion of the majority of industry-funded research. This, in turn, led to the more rigorous regulation on the neonicotinoid pesticides that was introduced in the logic of the precautionary principle.

However, this conclusion should not go too far and neglect the influence of other actors in the environmental field, such as various NGOs, various associations, media and strong public feeling regarding the issue. Non-political actors exercising informal pressures were active not only during the process of risk assessment, but also before the Commission made its re- quest to EFSA to assess the risks neonicotinoids posed to bees. EFSA was pressured to use substantiating strategies to support strong public feeling, values and interests in the environmental field. In so doing, EFSA was highly successful in maintaining public trust by demonstrating its independence of the interests of industry and by exclusively relying on academic evidence, i.e. hypothetically the most reliable and unbiased evidence, which is crucial given the mission of EFSA - to gain and maintain public trust in its activities on food safety assurance. It seems that empirical evidence from the case study supports the theoretical argument: expertise organisations are likely to survive and grow in terms of power and influence if the organisation's internal capacity to deal with external pressure matches with external demands.

This study develops starting points for further research. The article has introduced a general theory explaining the differences in scientific expertise use, which have been tested only partly and in one particular context, i.e. one issue within one EU regulatory agency. However, the theoretical argument of the article could be said to be relevant to all expertise bodies acting on the basis of scientific expertise, including the Commission, comitology committees, national agencies, international organisations, or other executive, regulatory or information bodies whose expertise feeds into various policy-making stages. Testing the theoretical explanations outlined in the article in different contexts would clearly be a requisite for further research.

\section{Acknowledgements}

The article was presented at the ECPR General Conference in Glasgow, at the $5^{\text {th }}$ ECPR Graduate Student Conference in Innsbruck, and at the Ludwig-MaximiliansUniversität colloquium in Munich. The author thanks the participants of these conferences, as well as Berthold Rittberger, Sandra Eckert, Eva Ruffing, Holger Straßheim, Verena Simmel, Bernhard Zangl, Michael Blauberger, Alexander Spencer, Andreas Kruck, Karina Shyrokykh, Stefan Jagdhuber, Nina Guérin, Moritz Weiß and last but not least Andrius Tilvikas for their insightful comments and suggestions. Eugenija Golubova deserves credit for transcribing the interviews. I also thank the anonymous reviewers and the guest editors, Åse Gornitzka and Cathrine Holst, for their highly constructive comments.

\section{Conflict of Interests}

The author declares no conflict of interests.

\section{References}

Blatter, J., \& Haverland, M. (2012). Designing Case Studies. Exploratory Approaches in Small-n Re- 
search. Houndsmill, Basingstoke, Hampshire: Palgrave Macmillan

Blom, T., Radulova, E., \& Arnold, C. (2008). Theorizing modes of governance in the EU: Institutional design and informational complexity. European Governance Articles. Retrieved from http://www.mzes.unimannheim.de/projekte/typo3/site/fileadmin/wp/ pdf/egp-connex-C-08-04.pdf

Borràs, S., Koutalakis, C., \& Wendler, F. (2007). European agencies and input legitimacy: EFSA, EMEA and EPO in the post-delegation phase. Journal of European Integration, 29(5), 583-600.

Boswell, C. (2008). The political functions of expert knowledge: Knowledge and legitimation in European Union immigration policy. Journal of European Public Policy, 15(4), 471-488.

Boswell, C. (2009a). Knowledge, legitimation and the politics of risk: The functions of research in public debates on migration. Political Studies, 57, 165-186.

Boswell, C. (2009b). The Political Uses of Expert Knowledge: Immigration Policy and Social Research. Cambridge: Cambridge University Press.

Brunsson, N. (1989). The Organization of Hypocrisy: Talk, Decisions and Actions in Organizations. Chichester: John Wiley \& Sons.

Busuioc, M., Groenleer, M., \& Trondal, J. (Eds.). (2012). The Agency Phenomenon in the European Union: Emergence, Institutionalisation and Everyday Decision-making. Manchester: Manchester University Press.

Campbell, P. J. (2013). Declining European bee health: Banning the neonicotinoids is not the answer. Outlooks on Pest Management. Retrieved from http://www3.syngenta.com/country/ca/SiteCollecti onDocuments/Corporate/Campbell_2013_E.pdf

Chiti, E. (2013). European agencies' rulemaking: Powers, procedures and assessment. European Law Journal, 19(1), 93-110.

Coen, D., \& Thatcher, M. (2005). The new governance of markets and non-majoritarian regulators. Governance, 18(3), 329-346.

Dehousse, R. (2008). Delegation of powers in the European Union: The need for a multi-principals model. Western European Politics, 31(4), 789-805.

DiMaggio, P. J., \& Powell, W. W. (1983). The iron cage revisited: Institutional isomorphism and collective rationality in organizational fields. American Sociological Review, 48(2), 147-160.

EFSA. (n.d.). Requests and mandates. Retrieved from http://www.efsa.europa.eu/en/request/requests.h tm

EFSA. (2013a). Conclusion on the peer review of the pesticide risk assessment for bees for the active substance clothianidin. Retrieved from http:// www.efsa.europa.eu/en/efsajournal/pub/3066.htm

EFSA. (2013b). Conclusion on the peer review of the pesticide risk assessment for bees for the active substance imidacloprid. Retrieved from http:// www.efsa.europa.eu/en/efsajournal/pub/3068.htm

EFSA. (2013c). Conclusion on the peer review of the pesticide risk assessment for bees for the active substance thiamethoxam. Retrieved from http:// www.efsa.europa.eu/en/efsajournal/pub/3067.htm

EFSA. (2013d). Press release: EFSA identifies risks to bees from neonicotinoids. Retrieved from http:// www.efsa.europa.eu/en/press/news/130116.htm? wtrl=01

European Commission. (2012). Mandate for scientific and technical assistance (EFSA Conclusions) in accordance with Article 21 of Regulation (EC) No $1107 / 2009$ to perform an evaluation of neonicotinoids as regards the risk to bees. Retrieved from http://ec.europa.eu/food/animal/liveanimals/bees/ docs/1107_2009_en.pdf

European Commission. (2013). Implementing Regulation (EU) No 540/2011, as regards the conditions of approval of the active substances clothianidin, thiamethoxam and imidacloprid, and prohibiting the use and sale of seeds treated with plant protection products containing those active substances. Official Journal of the European Union. Retrieved from http://eur-lex.europa.eu/LexUriServ/LexUriServ.do ?uri=OJ:L:2013:139:0012:0026:EN:PDF

European Commission. (2014). Honey bees. Retrieved from http://ec.europa.eu/food/animal/liveanimals/ bees/index_en.htm

European Parliament, \& Council of the European Union. (2002). Regulation (EC) No 178/2002 European Parliament and the Council of the European Union of 28 January 2002 laying down the general principles and requirements of food law, establishing the European Food Safety Authority and laying down procedures in matters of food safety. Official Journal of the European Union. Retrieved from http://eur-lex.europa.eu/LexUriServ/LexUriServ.do ?uri=OJ:L:2002:031:0001:0024:EN:PDF

Groenleer, M. (2009). The Autonomy of European Union agencies: A Comparative Study of Institutional Development. Delft: Eburon.

Henry M., Beguin, M., Requier, F., Rollin, O., Odoux, J.F., Aupinel, P., Aptel, J., Tchamitchian, S., \& Decourtye, A. (2012). A common pesticide decreases foraging success and survival in honey bees. Science, 336(6079), 348-350.

Herbst, S. (2003). Political authority in a mediated age. Theory and Society, 32, 481-503.

Héritier, A., \& Rhodes, M. (2011). Conclusion: New Modes of Governance: Emergence, Execution, Evolution and Evaluation. In A. Héritier \& M. Rhodes (Eds.), New Modes of Governance in Europe, 163174. Houndsmill, Basingstoke, Hampshire: Palgrave Macmillan.

Hertin, J., Turnpenny, J., Jordan, A., Nilsson, M., Russel, D., \& Nykvist, B. (2007). Rationalising the policy 
mess? Ex ante policy assessment and the utilisation of knowledge in the policy process. Environment and Planning, 41(5), 1185-1200.

Hofmann, H. C. H., \& Morini, A. (2012). Constitutional aspect of the pluralisation of the EU executive through "agencification". European Law Review, 4(37), 419-443.

Kelemen, D. R. (2002). The politics of "Eurocratic" structure and the new European agencies. West European Politics, 25(4), 93-118.

Maggetti, M. (2012). Regulation in Practice. Colchester: ECPR Press.

Majone, G. (1996). Regulating Europe. London: Routledge.

Majone, G. (2002). What price safety? The precautionary principle and its policy implications. Journal of Common Market Studies, 40(1), 89-109.

Meyer, J., \& Rowan, B. (1991). Institutionalized Organizations: Formal Structure as Myth and Ceremony. In W. Powell \& P. DiMaggio (Eds.), The New Institutionalism in Organizational Analysis. Chicago, Illinois: University of Chicago Press.

Radaelli, C. M. (1995). The role of knowledge in the policy process. Journal of European Public Policy, 2(2), 159-183.

Radaelli, C. M. (2009). Measuring policy learning across Europe: Regulatory impact assessment in comparative perspective. Journal of European Public Policy, 16(8), 1145-1164.

Rimkute, D. \& Haverland, M. (2014). How does the European Commission use scientific expertise? Results from a survey of scientific members of the Commission's expert committees. Comparative European Politics. doi:10.1057/cep.2013.32

Rohlfing, I. (2012). Case Studies and Causal Inference: An Integrative Framework. Basingstoke: Palgrave Macmillan.

Schrefler, L. (2010). The usage of scientific knowledge by independent regulatory agencies. Governance, 23(2), 309-330.

Schrefler, L. (2013). Economic Knowledge in Regulation: the Usage of Scientific Knowledge by Independent
Regulatory Agencies. Colchester: ECPR Press.

Scott, C. (1998). Agencies for European Regulatory Governance: A Regime Approach. In D. Geradin, R. Muñoz, \& N. Petit (Eds.), Regulation through Agencies in the EU. A New Paradigm of European Governance (pp. 67-88). Cheltenham: Edward Elgar.

Shapiro, M. (1997). The problems of independent agencies in the United States and the European Union. Journal of European Public Policy, 4(2), 276-297.

Skogstad, G. (2003). Legitimacy and/or policy effectiveness? Network governance and GMO regulation in the European Union. Journal of European Public Policy, 10(3), 321-338.

Tallberg, J. (2006). Executive Politics. In K. E. Jørgensen, M. Pollack, \& B. Rosamond (Eds.), Handbook of European Union politics (pp. 195-212). London: SAGE.

Thatcher, M., \& Stone Sweet, A. (2002). Theory and practice of delegation to non-majoritarian institutions. West European Politics, 25(1), 1-22.

Thatcher, M. (2002). Delegation to independent regulatory agencies: Pressures, functions and contextual mediation. West European politics, 25(1), 125-147.

Tosun, J. (2013). How EU handles uncertainty risks: Understanding the role of the precautionary principle. Journal of European Public Policy, 20(10), 1517-1528.

US Environmental Protection Agency. (2013). Colony Collapse Disorder: European Bans on Neonicotinoid Pesticides. Retrieved from http://www.epa.gov/ pesticides/about/intheworks/ccd-european-ban.html

Versluis, E., van Keulen, M., \& Stephenson, P. (2011). Analyzing the European Union Policy Process. Houndmills: Palgrave MacMillan.

Weiss, C. H. (1979). The many meanings of research utilization. Public Administration Review, 39, 426-431.

Whitehorn, P. R., O’Connor, S., Wackers, F. L., \& Goulson, D. (2012). Neonicotinoid pesticide reduces bumble bee colony growth and queen production. Science, 336(6079), 351-352.

Wonka, A., \& Rittberger, B. (2010). Credibility, complexity and uncertainty: Explaining the institutional independence of $29 \mathrm{EU}$ agencies. West European Politics, 33(4), 730-752.

\section{About the Author}

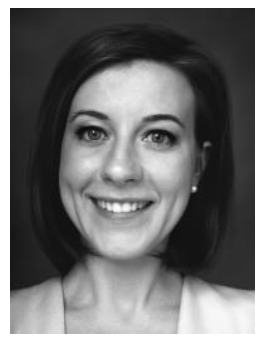

Dovilè Rimkutè

Dovile Rimkute has been a PhD candidate in Political Science at the Ludwig-Maximilians-Universität (LMU) München since March 2014. Before joining LMU she held a Marie Curie scholarship for Early Stage Researchers and worked as a Research Associate at the Mannheim Centre for European Social Research. Her research interests cover a range of European Union policy/decision-making topics, however, risk regulation and evidence-based governance in EU regulatory processes and factors affecting it take a central role. In her current research, Dovile investigates the effect of external demands and internal capacities of European Union regulatory agencies on the patterns of scientific expertise use. 